\title{
LA ALFARERÍA DE EL POBLADITO (TUMBAYA, JUJUY, ARGENTINA). UNA APROXIMACIÓN AL PERÍODO INTERMEDIO TARDÍO DE TUMBAYA A PARTIR DEL ESTUDIO CERÁMICO
}

\author{
EL POBLADITO POTTERY (TUMBAYA, JUJUY, ARGENTINA). \\ AN EXPLORATION OF THE LATE INTERMEDIATE PERIOD \\ AT TUMBAYA FROM A CERAMIC PERSPECTIVE
}

Agustina Scaro ${ }^{1}$

\begin{abstract}
En este trabajo se presentan los resultados obtenidos del análisis de la cerámica recuperada en el Recinto 2 de El Pobladito, a partir de una perspectiva morfo-decorativa y contextual, en el marco de estudios estilísticos. El Pobladito, ubicado en el sector centro-sur de quebrada de Humahuaca, ha sido ocupado durante el siglo XIII de acuerdo con fechados obtenidos hasta el momento, se trata del único asentamiento del período Intermedio Tardío conocido hasta ahora para el sector. El establecimiento del repertorio morfológico e iconográfico de la alfarería permitió vincular a El Pobladito con contextos contemporáneos del asentamiento cercano Pucara de Volcán con el fin de caracterizar procesos de identidad así como de interacción social e integración regional en el sector centro-sur. Palabras claves: período Intermedio Tardío, quebrada de Humahuaca, cerámica.
\end{abstract}

The results of pottery analyses at El Pobladito Enclosure 2 are presented here using a morpho-decorative and contextual perspective as part of a study of style. El Pobladito, found in the south-central sector of the Quebrada de Humahuaca, was occupied during the 13th century $A D$ according to current dates. It represents the only Late Intermediate Period settlement in this area. The morphological and iconographic repertory of El Pobladito, when compared with the pottery from contemporary contexts recovered at Pucara de Volcán, reveals social interaction, regional integration and identity processes from the south-central sector.

Key words: Late Intermediate Period, Quebrada de Humahuaca, pottery.

Con el fin de contribuir al conocimiento del período Intermedio Tardío (1.000 d.C. a 1.410/80 d.C. sensu González y Pérez 1972) en quebrada de Humahuaca, abordamos el estudio de la alfarería recuperada en el Recinto 2 del asentamiento El Pobladito desde una perspectiva estilística, haciendo hincapié en aspectos morfo-decorativos. Esto, considerando que la cerámica es una de las labores productivas más generalizadas del pasado y que permite conocer diversos usos y comportamientos cotidianos (Skibo y Feinmann 1999). Además, la alfarería, en tanto un elemento activo de las relaciones sociales, habría jugado un rol significativo en la construcción de la identidad, diferenciación social y procesos de interacción entre distintas sociedades (Bugliani 2008).

El Pobladito es el único asentamiento ocupado solamente durante el período Intermedio Tardío (en adelante PIT) en el sector centro-sur de la quebrada, según las investigaciones realizadas hasta el momento. Por esta razón, su estudio resulta fértil en el análisis de la integración regional de los sitios de la zona, considerando las similitudes arquitectónicas observadas entre El Pobladito y Pucara de Volcán (en adelante P.Volcán), un asentamiento ocupado desde el siglo XIII pero que tuvo su mayor desarrollo durante momentos incaicos, perdurando hasta el siglo XVI (Fumagalli 1998). A partir de los estudios estílisticos de vasijas, discutimos el rol de El Pobladito en el período en cuestión, en relación con niveles contemporáneos de los basureros Tum1B1 y Tum1B3 de P.Volcán (Cremonte y Nieva 2003), considerando aspectos identitariosy procesos de interacción social a corta y larga distancia en los cuales habrían participado.

La quebrada de Humahuaca se extiende por más de $130 \mathrm{~km}$ en el centro de la provincia de Jujuy. Su sector centro-sur (Figura 1) está delimitado hacia el norte por la quebrada de Purmamarca y hacia el sur por el Arroyo del Medio. Esta zona se caracteriza

1 CONICET- Instituto de Geología y Minería, Universidad Nacional de Jujuy. Av. Bolivia 1661. San Salvador de Jujuy (4600), Argentina.eowyn939@gmail.com 


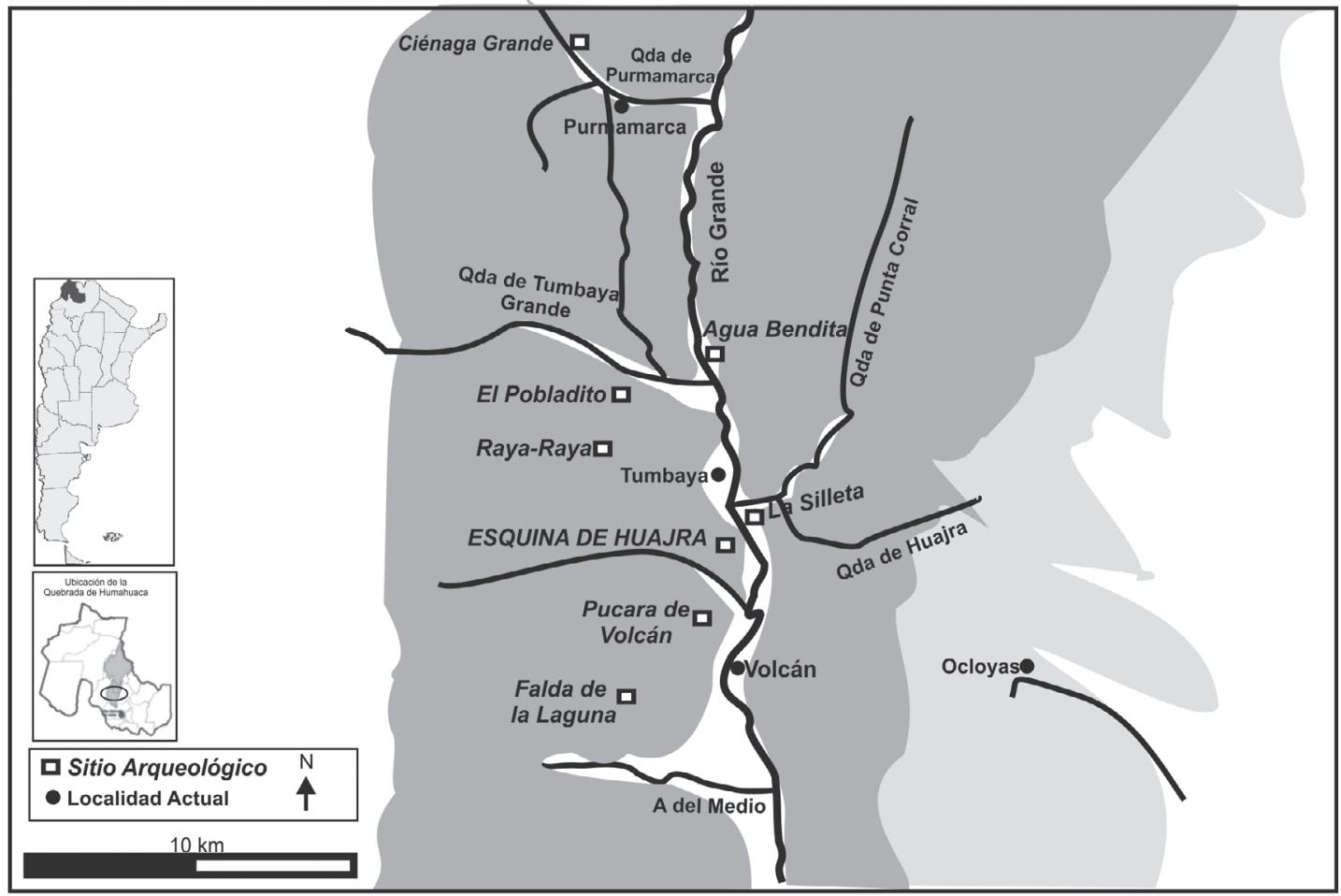

Figura 1. Localización de los sitios del sector centro-sur de quebrada de Humahuaca.

Location of the sites in the south-central sector of the Quebrada de Humahuaca.

por la cercanía de las unidades medioambientales y geomorfológicas de puna, quebrada y Yungas, permitiendo acceder a gran variedad de recursos a corta distancia. La quebrada de Tumbaya Grande al oeste y la de Huajra al este son pasos directos que conectan el sector con la puna y las Yungas, respectivamente.

Las investigaciones que se están llevando a cabo en el sector centro-sur permitieron comenzar a caracterizar su ocupación prehispánica. Cerámica de Tradición San Francisco (Dougherty 1974; Ortiz 2007) fue hallada en un perfil expuesto en el área agrícola Raya-Raya. La misma se suma a la recuperada en P.Volcán, dos metros por debajo de la ocupación del PIT y fechada a inicios de la era (Fumagalli y Cremonte 2002). Este hallazgo permite plantear que en la zona se habrían instalado de forma permanente grupos provenientes de la cuenca del río San Francisco, en la zona de Yungas.

El sitio El Observatorio presentaría una ocupación Isla (ca. 700-1.000 d.C. sensu Tarragó 1977) de acuerdo a la cerámica hallada en superficie, indicando que hacia el siglo $\mathrm{X}$ habrían grupos instalados en la entrada de la quebrada de la mina.
El Observatorio se suma a La Junta en la indagación de la presencia Isla en el sector centro-sur (Cremonte et al. 2011) y permitiría contextualizar las pocas vasijas Isla procedentes de P.Volcán halladas por Gatto (1946).

El PIT en la zona está evidenciado en El Pobladito y en la ocupación inicial de P.Volcán. Las similitudes observadas a nivel arquitectónico y de configuración espacial entre ambos, diferentes a la arquitectura registrada en sitios más septentrionales de la quebrada, ha permitido considerar desde un inicio su vinculación durante este momento, la cual es discutida más abajo en relación con la alfarería. Asimismo, el análisis arquitectónico de Raya-Raya permite considerar que gran parte de las terrazas agrícolas habrían estado en funcionamiento, y probablemente también el sitio La Silleta, ubicado en la entrada de la quebrada de Huajra, cuyo estudio es aún preliminar.

Durante el período Incaico habrían surgido Esquina de Huajra y Las Ventanitas, mientras que P.Volcán y Raya-Raya habrían tenido su mayor desarrollo. Esquina de Huajra pudo haber sido clave en la articulación económica entre zonas ecológicas 
diferentes; asimismo, la incidencia de vasijas no locales de diferentes estilos y usos procedentes de las tierras altas y el despliegue de formas, acabados, tratamientos de superficie y pastas finas funcionarían como marcadores de estatus y de interacción de los pobladores del asentamiento (Cremonte et al. 2007).

\section{El Período Intermedio Tardío en Quebrada de Humahuaca}

El PIT en los Andes Sur-Centrales (ca. 1.000$1.430 / 80$ d.C.) ha sido caracterizado como un momento de cambios y nuevos procesos, como el aumento demográfico, la fragmentación política, la intensificación en el manejo de recursos naturales por irrigación, la explotación ganadera intensiva y el control de diversos pisos ecológicos, tanto en el Noroeste Argentino como en gran parte de los Andes Sur-Centrales (Arkush 2009; Nielsen 2006; Tarragó 2000). La fragmentación política habría generado grupos organizados de manera segmentaria, dentro de los cuales interactuaban subgrupos que mantenían su identidad y autonomía relativa, creando espacios interdigitados (Arkush 2009; Martínez 1989; Nielsen 2006; Platt 2010).

Los procesos sociales que tuvieron lugar durante el PIT habrían estado enmarcados en situaciones de conflicto y fragmentación, reflejadas en cambios en el patrón de asentamiento, ya que los sitios comienzan a ubicarse en lugares altos con ventajas defensivas. Este estado de conflicto endémico se extendería a lo largo de los Andes Sur-Centrales, existiendo evidencias de luchas intergrupales y violencia desde por lo menos el norte del Perú hasta el Noroeste Argentino y norte de Chile (Arkush 2008; Nielsen 2006; Schiappacasse et al. 1989; Torres-Rouff et al. 2005); si bien, y como señalan Arkush y Tung (2013), el conflicto habría sido más intenso en las tierras altas que en la zona de valles bajos y la costa. De acuerdo con las autoras, en las zonas más bajas se observan focos de paz y conflicto vinculados a una mayor integración política, que habría logrado suprimir el conflicto interno y disminuir la amenaza externa. En el marco de esta situación inestable de conflictos y alianzas cambiantes, existió intercambio a corta y larga distancia, donde los poblados ubicados en altura habrían funcionado como puertos de intercambio (Ruiz y Albeck 1997; Tarragó 2000). Dentro de estos procesos, la cerámica formaría parte de "estilos emblemáticos" surgidos para transmitir mensajes acerca de la identidad de estos nuevos grupos (Ortiz y Delgado 2002).

En quebrada de Humahuaca, a inicios del primer milenio comienza a aumentar la cantidad de sitios y su densidad edilicia, ocupándose áreas bajas y de fácil acceso. Es recién hacia el siglo XIII, en la segunda mitad del PIT, que se observan los mayores cambios. La densidad de sitios aumentó de forma significativa, concentrándose principalmente en el fondo de valle del río Grande. Además, aparecieron asentamientos conglomerados ubicados en lugares altos con ventajas defensivas, los cuales habrían tenido una ocupación prolongada (Nielsen 2001, 2006; Tarragó 2000). Sin embargo, los estudios que se están realizando en asentamientos en altura de este período, como P.Volcán o Pucara de Tilcara (en adelante P.Tilcara), revelan que su mayor desarrollo correspondería a momentos incaicos, mientras que la ocupación del PIT se encuentra muy desdibujada (Fumagalli 1998; Otero 2013).

En relación con la alfarería, no se han estudiado en profundidad las características morfo-decorativas de la cerámica local de la quebrada que serían propias del PIT y que permitirían diferenciarla del estilo local del período Incaico. Si bien se reconoce la adopción de nuevas formas y algunos diseños, se hace hincapié en la continuidad del estilo Humahuaca (Nielsen 2001). Avances en este sentido fueron realizados por Cremonte y Solís (1998) al estudiar la cerámica de basureros de P.Volcán.

En el marco de la problemática mencionada, El Pobladito, un asentamiento del PIT en el cual no se han registrado otras ocupaciones, es hasta ahora un ejemplo único para comenzar a definir el momento previo a la llegada de los Incas en el sector centrosur de quebrada de Humahuaca.

\section{Procedimiento de Análisis: desde la Perspectiva del Estilo}

El análisis cerámico se abordó a partir de los estudios estilísticos, estableciendo un repertorio morfológico-decorativo que pudiera dar cuenta de identidades sociales locales y redes de interacción. Esto, considerando que, tal como lo señalan Conkey y Hastorf (1990), el estilo no está separado de los contextos sociales que dan a la cultura material su valor social.

El estilo es entendido desde una perspectiva activa, como un modo de representación socialmente construido y que posee una configuración particular, 
cuyos contenidos solo pueden ser interpretados en relación con el contexto en el cual es producido y consumido (Bugliani 2008). Al analizar la cerámica desde esta propuesta, consideramos que los aspectos iconográficos, morfológicos y tecnológicos están interrelacionados, configurando un modo de hacer particular. En este sentido y como propone Knappett (2005), el significado no se limita a los objetos que podrían considerarse "estéticos" o "especiales", sino que también está presente en los objetos cotidianos.

El análisis morfológico fue realizado considerando las clasificaciones propuestas para quebrada de Humahuaca (Cremonte et al. 1997; Nielsen 2001; Otero 2006) y tomando como base los lineamientos de Balfet et al. (1983). En principio se establecieron Grupos Morfológicos Generales a partir de la relación entre la altura de las piezas y su diámetro máximo, mínimo y de abertura. Cada grupo fue subdividido en variedades de acuerdo con los puntos del perfil, las características del borde y del cuello de las vasijas, y el espesor de las paredes. Este enfoque resultó útil para realizar una clasificación morfológica de un conjunto altamente fragmentado como el que se enfrenta en este caso.

El análisis del diseño siguió la propuesta de Jernigan (1986) para un acercamiento no jerárquico a los motivos, buscando identificar unidades a partir de su repetición en distintos recipientes, pero sin dar por sentado que existen niveles entre las mismas, relacionados con etapas en su planificación o ejecución. El análisis incluyó la identificación de técnicas decorativas y el establecimiento del protocolo de motivos. Asimismo, se consideraron los lineamientos planteados por Cremonte y Solís (1998) en relación a las diferencias entre el conjunto cerámico del PIT y el perteneciente a momentos incaicos. Las autoras han registrado motivos distintos, así como particularidades en las características de los reticulados, el ancho del trazo y el tratamiento y color de la superficie.

\section{Un Asentamiento del Período Intermedio Tardío}

El Pobladito (Figura 2) es un asentamiento emplazado en una antigua terraza aluvional a 2.400 msm. Está localizado en la quebrada de Tumbaya Grande, como dijimos, un paso directo hacia la puna. La misma presenta una gran variedad de recursos (Solís y Rivero 1994), entre los cuales se destacan diversas materias primas, pasturas localizadas en antiguas terrazas aluviales y tierras aptas para el cultivo. Estas últimas ubicadas en el fondo de valle de la cuenca de Tumbaya Grande y principalmente en Raya-Raya, un área de más de 80 hectáreas de estructuras agrícolas construidas en distintos momentos de la historia ocupacional de la zona. Por otro lado, el fondo de valle del río Grande habría aportado recursos lacustres ya que estuvo cubierto por un paleolago que se extendía desde el Arroyo del Medio hasta la zona de Tumbaya Grande (Solís y Rivero 1994).

El Pobladito es un conglomerado de 432 metros de largo por 25 a 86 metros de ancho que cubre aproximadamente dos hectáreas. Se compone de 112 recintos orientados con su lado mayor de noreste a suroeste, de planta rectangular con sus ángulos redondeados y muros dobles de $50 \mathrm{~cm}$ a un metro de ancho. El conjunto se completa con siete recintos circulares.

Hasta el momento se excavaron tres recintos en distintos sectores del asentamiento. El Recinto 1 presenta una buena conservación a nivel arquitectónico, su excavación reveló la presencia de un estrato de relleno con escaso material cultural superpuesto al estrato estéril, el cual coincidía con los cimientos del recinto. Por su parte, el Recinto 3 posee $98 \mathrm{~m}^{2}$ de superficie y presenta un muro que lo divide en un espacio mayor y uno menor; la excavación de este último reveló una estratigrafía similar a la del Recinto 2, hallándose un único piso de ocupación, en el que se destaca la presencia de dos fogones en cubeta, huesos de camélidos, instrumentos líticos y cerámica de manufactura local. El Recinto 2 presentó la mayor cantidad de material cultural.

\section{El universo cerámico del Recinto 2}

El Recinto 2 tiene $21 \mathrm{~m}^{2}$ de superficie, la conservación de los muros es muy pobre, registrándose solamente parte del muro oeste y este con una altura de $50 \mathrm{~cm}$ sobre la superficie actual, así como los bloques que marcan el acceso al mismo. La excavación total reveló la presencia de tres estratos naturales de relleno, los dos superiores presentaban escaso material cultural, mientras que el tercero, correspondiente al relleno del piso de ocupación, presentaba mayor cantidad de hallazgos. Por debajo del tercer estrato y a $45 \mathrm{~cm}$ de profundidad fue hallado un piso de ocupación de espesor variable, teniendo mayor potencia hacia 


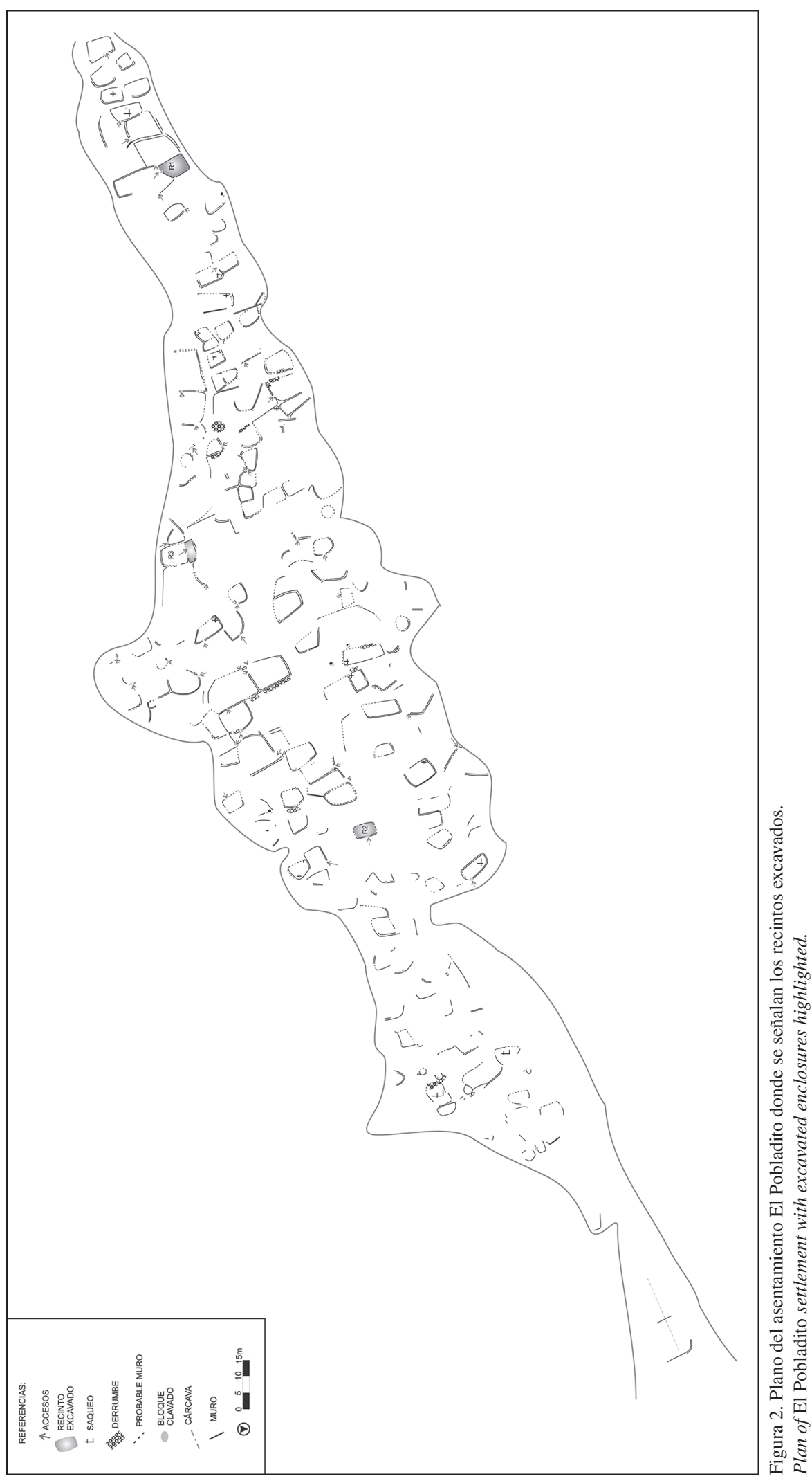


Tabla 1. Fechados obtenidos para el Recinto 2 de El Pobladito. Carbon dates for El Pobladito Enclosure 2.

\begin{tabular}{cccrr}
\hline Número Laboratorio & $\begin{array}{c}\text { Material utilizado / } \\
\text { Procedencia }\end{array}$ & $\begin{array}{c}\text { Edad radiocarbónica } \\
\text { (a.p.) }\end{array}$ & $\begin{array}{c}\text { Edad calibrada } \\
\text { (A.D.) } \pm 1 \delta\end{array}$ & $\begin{array}{c}\text { Edad calibrada } \\
\text { (A.D.) } \pm 2 \delta\end{array}$ \\
\hline LP-2742 & Carbón/Fogón & $470 \pm 70$ & $1.415-1.450$ & $1.330-1.608$ \\
UGA-8558 & Carbón /E7 & $650 \pm 25$ & $1.290-1.386$ & $1.282-1.392$ \\
LP-2877 & Hueso/Piso & $1.070 \pm 60$ & $895-1.021$ & $776-1.146$ \\
LP-2883 & Hueso/Piso & $690 \pm 50$ & $1.267-1.386$ & $1.228-1.398$ \\
\hline
\end{tabular}

el norte del recinto. Los fechados realizados sobre carbón vegetal y material óseo permiten ubicar esta ocupación en la segunda mitad del PIT (Tabla 1).

De los 1.700 fragmentos cerámicos recuperados fue posible identificar 56 vasijas que corresponden a estilos de manufactura local. Veintisiete de estas vasijas pertenecen al estilo Humahuaca Negro sobre Rojo (en adelante N/R) (Nielsen 2001), tres a Pucos Interior Negro Pulido (Bennet et al. 1945) y dos al estilo Angosto Chico Inciso (Bennet et al. 1945), asimismo están presentes dos vasijas rojas alisadas sin decoración y 21 vasijas ordinarias. Se halló también un Puco Bruñido rojo, un estilo no local de acuerdo con el análisis petrográfico realizado por Cremonte y Botto (2009), el cual indica un ambiente geológico volcánico que no existe en la quebrada.

A partir del análisis morfológico se identificaron siete grupos generales y sus variedades: Pucos, Escudillas, Fuentes, Vasos, Ollas, Tinajas y Cántaros. Como se ve en la Figura 3, las vasijas de servicio presentan una mayor variedad en cuanto a sus formas, predominando contornos simples principalmente de borde directo. En el caso de las piezas de almacenaje y cocción, se observa la recurrencia de bordes evertidos y cuellos rectos divergentes. Respecto de sus bases y asas, si bien en la mayoría de los casos no pueden ser asignadas a una forma específica debido a la fragmentación del material, se registraron bases plano-cóncavas y asas en cinta de sección rectangular u oval que estarían ubicadas en el cuerpo superior de las vasijas.

El conjunto cerámico presenta $49 \%$ de fragmentos decorados mediante diferentes técnicas (Figura 4). Principalmente están presentes los elementos pintados en negro sobre fondo rojo (10R 4/6RED) y, en menor medida, motivos incisos del estilo Angosto Chico Inciso, correspondientes a incisiones redondeadas y arrastradas pequeñas, ambas de poca profundidad. Algunas piezas están decoradas por medio del pulido y bruñido, como en el caso de los Pucos Interior Negro Pulido y del Puco Bruñido. Registramos también piezas rojas alisadas, correspondientes a un puco de contorno simple y borde directo y a una pieza de forma cilíndrica. En algunos casos las vasijas pintadas de rojo, ya sean Humahuaca N/R o alisadas sin decoración, de servicio o de cocciónalmacenaje, presentan un engobe fugitivo, debido a su aplicación postcocción.

El repertorio de decoraciones pintadas incluye la banda reticulada en línea gruesa de malla abierta, recurrente tanto en vasijas de servicio como en aquellas de preparación y almacenaje. Está presente asimismo el motivo de manos o "alas" en piezas de servicio, la guarda de triángulos negros y los semicírculos concéntricos en piezas de preparación/ almacenaje, así como líneas negras solas o formando guardas que aparecen en general asociadas a algunos de los otros motivos. Este repertorio permite comenzar a caracterizar los rasgos que serían diagnósticos para la alfarería del PIT, aunque no se descarta que la poca variedad registrada pueda estar vinculada al estado fragmentario del material recuperado.

\section{Uso y Consumo: la Cerámica en el Contexto del Recinto 2}

Como se observa en la Figura 5, el Recinto 2 presenta un gran fogón en su ángulo noroeste, vinculado a algunos bloques que habrían funcionado como superficies de apoyo. En el centro del mismo fue hallado un depósito subterráneo demarcado por clastos que contenía la parte distal de una trompeta de hueso de camélido y una pequeña mano de moler; próximo a este depósito se encontraba la base de una gran vasija cerrada que estaba sostenida por clastos para darle mayor estabilidad. En el sector sur se registró otro rasgo negativo, correspondiente a la huella de un poste limitada con clastos, que habría servido para sostener el techo. Finalmente, 


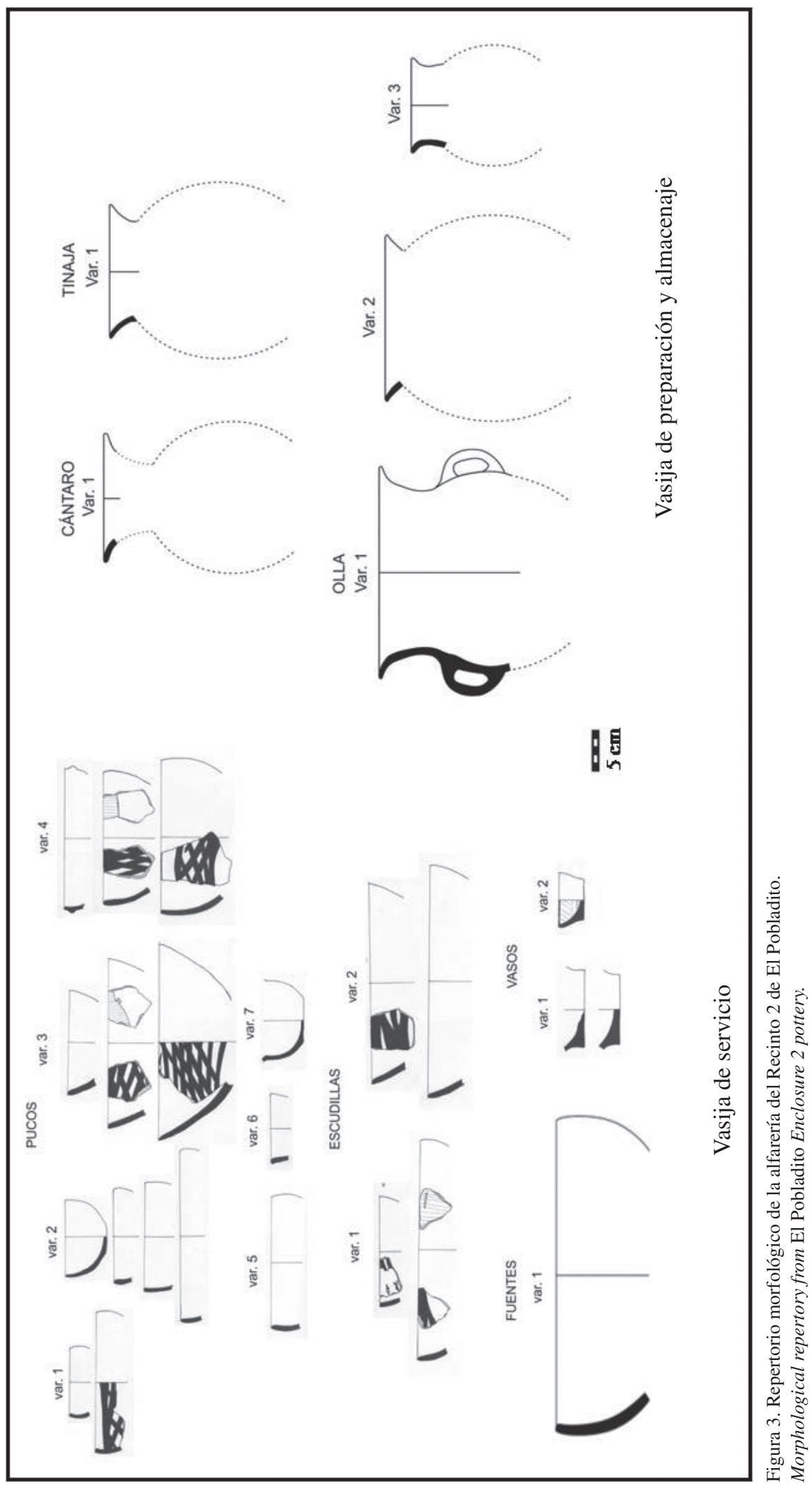




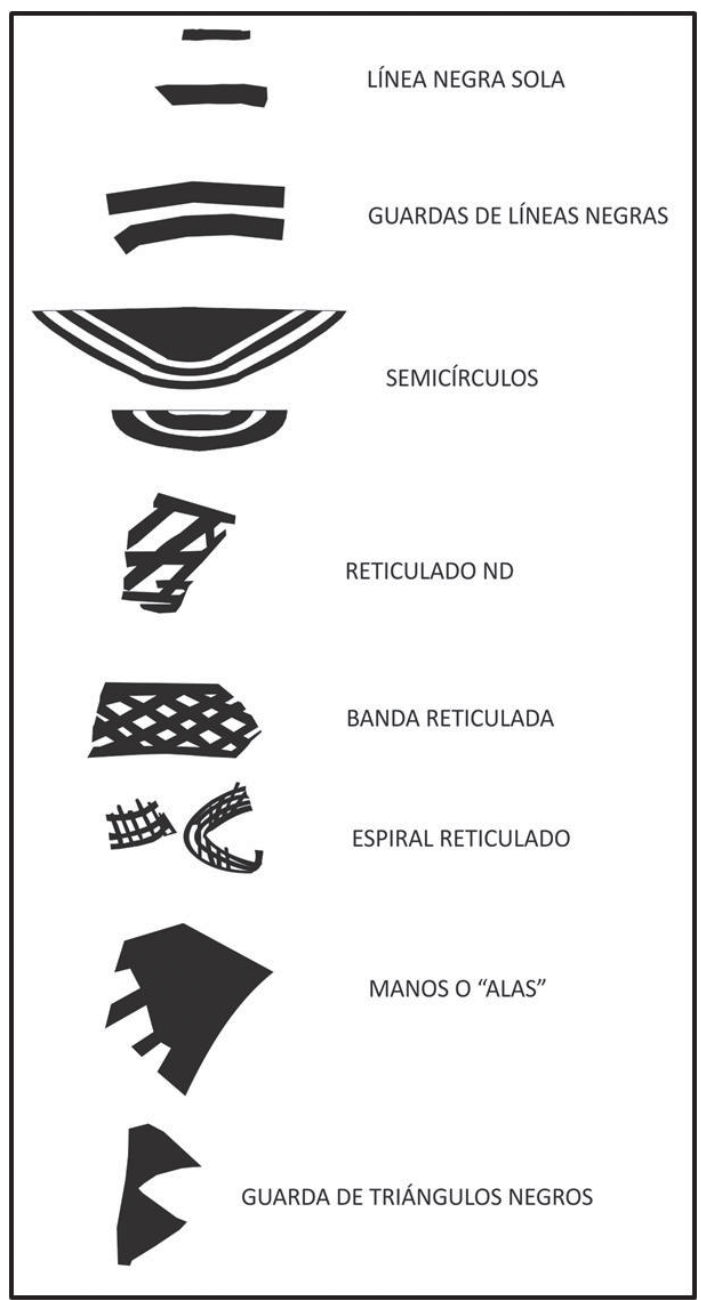

Figura 4. Repertorio decorativo de la alfarería del Recinto 2 de El Pobladito.

Iconographic repertory from El Pobladito Enclosure 2 pottery.

se registró el acceso en el muro este, señalado por dos grandes bloques rectangulares clavados en la superficie.

En este contexto, una importante concentración de fragmentos correspondientes a vasijas Humahuaca N/R alisado y ordinarias aparece en el centro del recinto y contra el muro norte, mientras que fragmentos de vasijas Humahuaca N/R pulido aparecen hacia el centro y sur. Asimismo, se observa una concentración diferenciada de fragmentos identificados como de vasijas de servicio y de preparación y almacenaje; las primeras aparecen hacia el sur del recinto, especialmente escudillas Humahuaca N/R, mientras que las vasijas de preparación y almacenaje, algunas con hollín, están concentradas hacia el norte, próximas al gran fogón hallado en el ángulo noroeste. Dentro del mismo se han recuperado fragmentos de vasijas y huesos de camélidos carbonizados.

Hacia el norte del recinto, además de la mayor concentración de vasijas de preparación y almacenaje ordinarias y N/R, se halló un grupo de falanges de camélido pintadas de rojo y negro, un cráneo de ave ubicado en el interior de una vasija ordinaria fragmentada, un silbato de cerámica y pigmento rojo. En el centro del recinto y sobre el piso de ocupación se recuperó una pequeña placa realizada en un mejillón (Bivalvia mytilidae), que provendría del litoral rocoso del norte de Chile.

Hacia el oeste del recinto, los fragmentos de vasijas locales aparecen vinculadas al fragmento de Puco Bruñido rojo, una gran cantidad de huesos de camélidos, lascas de obsidiana y manos de moler pequeñas. Estas probablemente hayan estado destinadas a la molienda de especias y condimentos como ají y sal, de acuerdo con su pequeño tamaño y al uso actual que le dan los pobladores de la zona, quienes las denominan "ajiceras". Asimismo, se recuperó una pequeña placa de metal con un orificio y un caracol terrestre entero del género Megalobulimus ${ }^{1}$. El caracol se encuentra en las Yungas al oriente de quebrada de Humahuaca, y en la actualidad se registra su uso como "tranquilizante de niños pequeños", siendo ubicado debajo de sus almohadas (Vargas Rodríguez comunicación personal 2012). Asociado a los elementos mencionados apareció una piedra plana que podría haber sido utilizada como superficie de apoyo.

Si bien la única alfarería no local corresponde al Puco Bruñido, existen otros elementos que darían cuenta de la vinculación de El Pobladito y probablemente de otras instalaciones del sector centro-sur con regiones diversas. Las lascas de obsidiana remiten a la puna, el caracol terrestre a las Yungas ubicadas al este y la placa de mejillón refleja vinculaciones con el norte de Chile (Figura 5).

La contigüidad material observada en el Recinto 2 permitió establecer probables áreas de actividad, vinculadas con las tareas domésticas que se habrían llevado a cabo en el mismo. Una probable área de descanso se ubicaría en el ángulo sureste, donde se observa un espacio protegido y con pocos hallazgos. El almacenaje se habría realizado en el ángulo suroeste, donde se han registrado fragmentos de cántaros y tinajas Humahuaca N/R y ordinarias y un espacio delimitado por clastos con fragmentos 


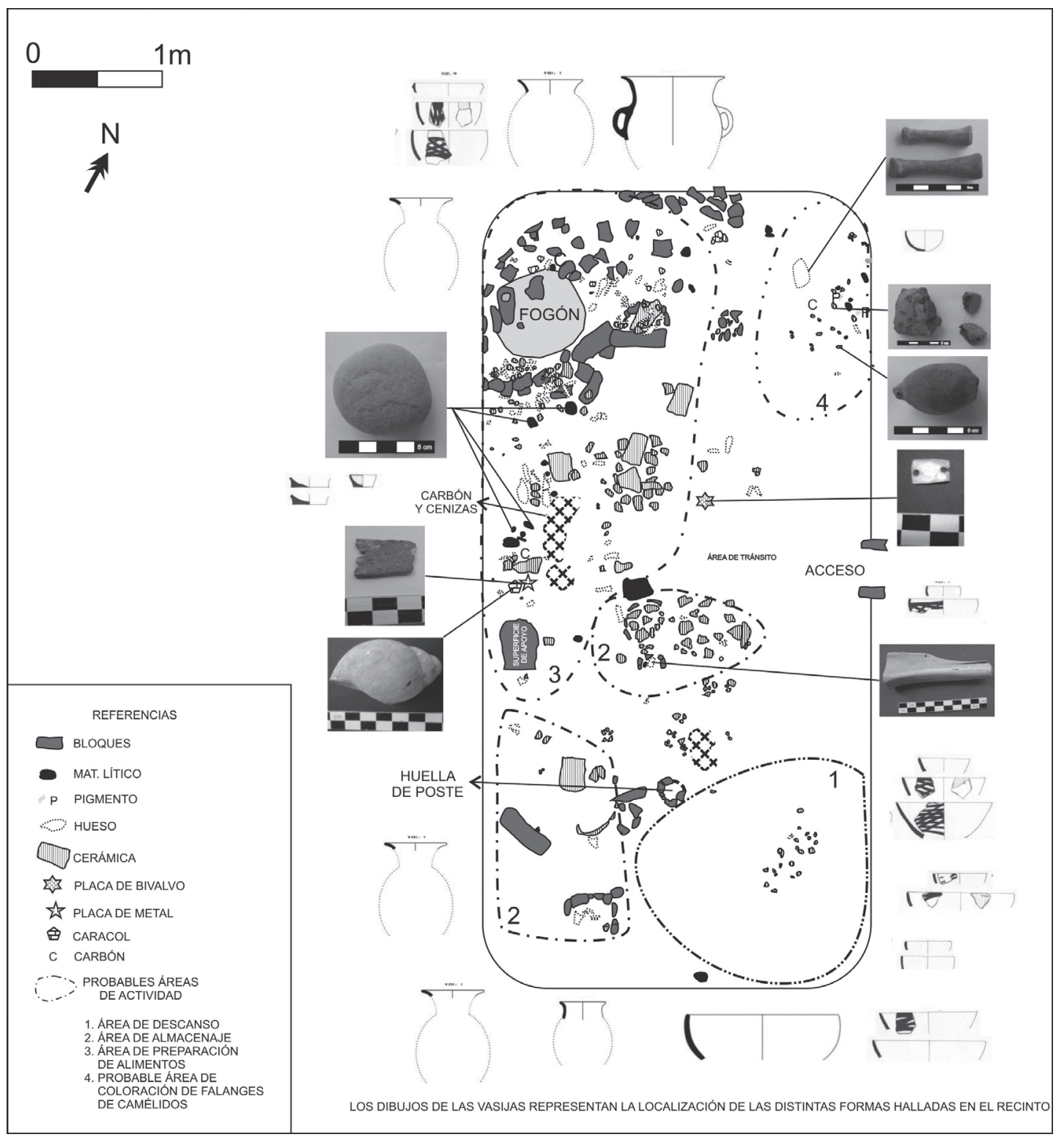

Figura 5. Contexto excavado en el Recinto 2.

Excavated context of Enclosure 2.

de una vasija Angosto Chico Inciso y huesos de camélidos. La presencia de fragmentos de vasijas de almacenaje en el centro del recinto, así como la base de vasija ordinaria sostenida por clastos y el depósito subterráneo ya mencionados, indican que este sector también habría sido utilizado en tareas de almacenaje.

El ángulo noroeste del recinto, donde se halló el fogón, habría sido utilizado para la preparación de alimentos, dada la presencia de vasijas de cocción (algunas con hollín), la concentración de huesos de camélido, las manos de moler y la superficie de apoyo. Sin embargo, es probable que también se hayan realizado otras tareas, como el hilado o la manufactura de instrumentos líticos, de acuerdo con la presencia de vasitos hilanderos y de lascas de obsidiana.

Si bien las actividades realizadas en el Recinto 2 serían predominantemente domésticas, consideramos que también habría sido el lugar de elaboración de elementos utilizados en actividades rituales, 
así como depósito de las mismas. En el ángulo noreste probablemente se habrían coloreado las falanges de camélidos, en el depósito subterráneo estaría almacenada la trompeta y en la vasija de almacenaje ordinaria próxima al fogón se habría guardado el cráneo de ave.

Los elementos especiales hallados en el Recinto 2, como la trompeta de hueso, las falanges pintadas, el silbato, las placas, el caracol y el cráneo de ave participarían del universo simbólico andino, de acuerdo con lo observado en distintos sitios de los Andes Sur-Centrales. Los mismos estarían vinculados a diversos rituales, cuyo escenario sería quizás la zona abierta que rodea al Recinto 2 , considerada como un espacio de participación comunitaria (Figura 2).

Nielsen (2007) ha caracterizado a las trompetas como instrumentos compuestos por tres piezas de hueso ensambladas mediante resina: boquilla, tubo intermedio y pabellón. El autor ha observado que las mismas se hallan principalmente en contextos funerarios andinos, siendo especialmente abundantes en quebrada de Humahuaca. Los ejércitos andinos tocaban las trompetas durante las batallas y también durante ceremonias propiciatorias, estando su sonido vinculado a la voz de las wak'a; en este sentido, las trompetas evocarían el poder de estos seres, por lo que podrían haber sido utilizadas para combatir otras amenazas, como plagas o granizo (Nielsen 2007). Asimismo, y como ha señalado Martínez (1995), las trompetas formarían parte de los emblemas de autoridad del mundo andino, con un real significado de amenaza de destrucción, reforzado por su vinculación con la guerra.

En relación con los cráneos de ave, se trataría de elementos de alto valor simbólico que aparecen en general en contextos funerarios, como en P.Tilcara, donde fue hallado un esqueleto de cóndor (Vultur gryphus) dentro de una cámara cilíndrica, así como huesos de ave formando parte del acompañamiento de cinco adultos y un niño (Debenedetti 1930). En contextos más tardíos, como los de Esquina de Huajra y Falda de Tilcara, cráneos de pato criollo (Cairina moschata) y pavita de monte (Meleagris ocellata) aparecen también como ajuares en tumbas (Bordach 2006; Scaro y Cremonte 2012).

Respecto de las falanges de camélido pintadas en rojo y negro, la aplicación de pigmento rojo a distintas piezas esqueletales de camélido ha sido registrada en diversos contextos excavados en los Andes (p.ej., Agüero y Uribe 2011). En el sector centro-sur, en un sondeo en La Silleta hemos registrado un hueso largo con uno de los extremos pintado de rojo y la superficie rebajada en el otro. A pesar de la presencia de huesos pintados de rojo, no tenemos hasta ahora referencias para el caso de falanges como las halladas en el Recinto 2. Sin embargo, cabe preguntarse si habrían sido elementos constitutivos de alguna ofrenda realizada en el marco de un ritual propiciatorio.

\section{Cerámica e Identidad en el Intermedio Tardío de Tumbaya}

Con el propósito de considerar la articulación entre los sitios de Tumbaya, se realizaron comparaciones de la cerámica de El Pobladito con conjuntos alfareros contemporáneos del P.Volcán, un asentamiento ubicado seis $\mathrm{km}$ al sur.

El P. Volcán se extiende por más de siete hectáreas y está conformado por aproximadamente 600 recintos de planta rectangular y ángulos redondeados. El asentamiento presenta un lapso ocupacional desde el 1.250 al 1.550 d.C.; sin embargo, su principal desarrollo habría tenido lugar durante la anexión de la quebrada al Incario (Fumagalli 1998).

Al comparar la alfarería recuperada en el Recinto 2 con los niveles inferiores de los basureros Tum1B1 y Tum1B3 del P.Volcán, fechados en el PIT (Cremonte y Nieva 2003; Cremonte y Solís 1998; Fumagalli 1998), se pudo observar que la cerámica de manufactura no local en los mencionados basureros es muy escasa, limitándose a unos pocos fragmentos de Pucos Bruñidos.

Tanto en El Pobladito como en P.Volcán, la alfarería del estilo Humahuaca N/R presenta superficies alisadas y decoradas con líneas medias a gruesas de manera predominante. Respecto de los motivos registrados en el mencionado estilo, el más recurrente en ambos sitios es la banda reticulada, que aparece en piezas de servicio y de preparación y almacenaje. Asimismo, los motivos registrados en El Pobladito (Figura 4) están también presentes en el P.Volcán, donde aparece además el motivo de espiral, no registrado en El Pobladito. Por otra parte, en ambos sitios aparecen vasijas rojas con engobe fugitivo y Pucos Interior Negro Pulido de borde directo con el exterior ordinario o rojo alisado.

Respecto de las formas de las vasijas, y a partir del repertorio establecido por Cremonte et al. (1997) para la colección $\mathrm{Gatto}^{2}$, fue posible observar que el material de P.Volcán contemporáneo con El Pobladito 
presenta una mayor variedad. En el primero están presentes formas no registradas en El Pobladito, como cuencos calceiformes, ollas globulares con asas labio-adheridas, baldes y tazones de asa lateral. Asimismo, resulta relevante la presencia en ambos sitios de escudillas de paredes rectas divergentes, decoradas con una banda reticulada en su borde interno.

A las semejanzas registradas en la alfarería se suman las observadas en la arquitectura, ya que tanto El Pobladito como P.Volcán son conglomerados localizados sobre terrazas aluvionales antiguas, conformados por recintos rectangulares de ángulos redondeados y con su lado mayor orientado de noroeste a suroeste. Estas características arquitectónicas difieren de las halladas en sitios contemporáneos localizados más al norte en quebrada de Humahuaca (Nielsen et al. 2004; Rivolta 2005, 2007; Taboada 2003; Zaburlín 2009), pero como han señalado Cremonte y Fumagalli (1997), remiten a sitios de la quebrada del Toro, como Santa Rosa de Tastil y Morohuasi.

\section{Conclusiones}

El estudio presentado en estas páginas permitió aislar un conjunto de atributos que consideramos diagnóstico del PIT en el sector centro-sur de quebrada de Humahuaca (Figura 6), y que permite caracterizar estas materialidades preincaicas. Dichos atributos corresponden a la decoración en negro sobre rojo, el predominio de superficies alisadas $\mathrm{y}$ en algunos casos con engobe rojo fugitivo. Los elementos decorativos registrados para este momento son las manos o "alas" y espirales reticuladas en piezas de servicio, guardas de triángulos negros y semicírculos concéntricos en vasijas de preparación y almacenaje, y en mayor proporción la banda reticulada, que aparece tanto en piezas de servicio como de preparación y almacenaje. Si bien estos motivos son recurrentes en la quebrada, el hecho de que estén ejecutados principalmente en líneas medias a gruesas, y que los reticulados sean de malla abierta y forma romboidal, así como la presencia de engobe rojo fugitivo, da cuenta de particularidades en el sector, corroborando y ampliando lo observado previamente para P.Volcán (Cremonte y Solís 1998). A nivel morfológico, la presencia predominante de escudillas de paredes rectas divergentes se presenta como una característica del sector para este momento. Asimismo, el análisis permite contar con una ubicación temporal precisa para el estilo Angosto Chico Inciso de manufactura local y para los Pucos Bruñidos, ambas modalidades que

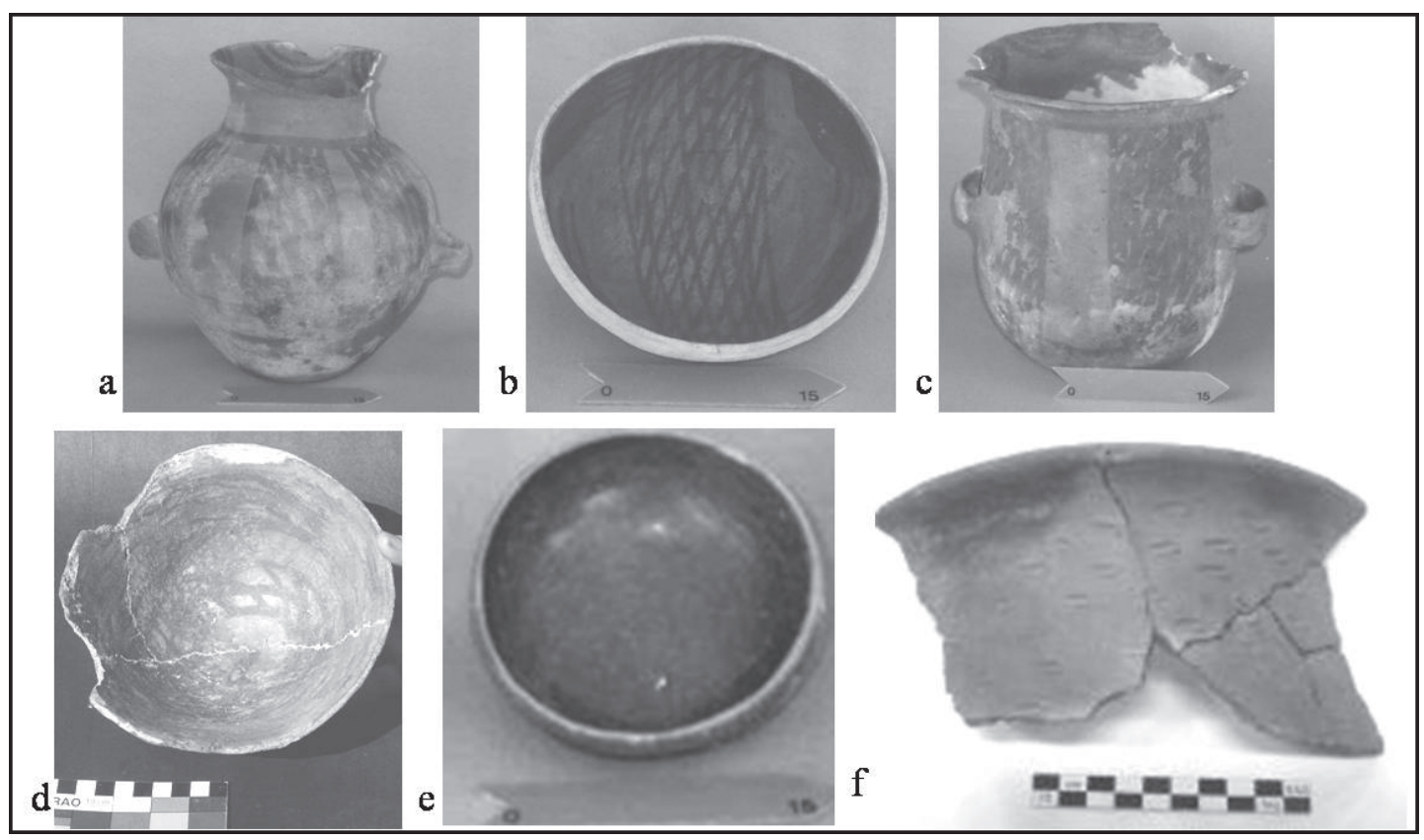

Figura 6. Conjunto cerámico del período Intermedio Tardío. (a-d) Vasijas Humahuaca N/R. (e) Puco Bruñido. (f) Angosto Chico Inciso. Late Intermediate Period ceramic assemblage. (a-d) Humahuaca Back on Red vessels. (e) Puco Bruñido Polished or Burnished Bowl. (f) Angosto Chico Incised. 
adquieren mayor popularidad durante el Incaico (Cremonte y Botto 2009).

El análisis cerámico de El Pobladito y su comparación con el material cerámico contemporáneo de P.Volcán, permitió plantear que estos asentamientos habrían estado articulados durante el PIT de acuerdo con las similitudes registradas en la alfarería, su arquitectura y configuración espacial. Estos asentamientos y el área agrícola de Raya-Raya formarían parte de un mismo territorio, cuyo surgimiento se vincularía a cambios y nuevos procesos que caracterizan a este momento, relacionados a situaciones de fragmentación política y potencial conflicto (Arkush 2009; Nielsen 2006; Tarragó 2000). En el marco de estos procesos, El Pobladito y P.Volcán se integrarían a nivel supracomunitario, probablemente en el marco de relaciones de igualdad y de jerarquía que constituirían una red dinámica, cohesionándose mediante acuerdos político-económicos para resistir presiones externas (Santoro et al. 2004). Dentro de este espacio, El Pobladito habría estado vinculado con el aprovechamiento de Raya-Raya y de otros recursos de la quebrada de Tumbaya Grande y probablemente también con el tránsito hacia las tierras altas, ya que su ubicación en la mencionada quebrada, un paso directo a la puna jujeña, le habría permitido tener control visual y un rápido acceso al área agrícola de Raya-Raya, así como al camino que conduce a las tierras altas, el cual es utilizado actualmente. Asimismo, habría sido escenario de rituales de acuerdo con los hallazgos registrados en el Recinto 2, vinculados al espacio de participación comunitaria que lo rodea.

En relación con lo propuesto por Cremonte y Fumagalli (1997) para P.Volcán, consideramos que el sector centro-sur se habría constituido como un territorio con amplias esferas de interacción. Sus habitantes estarían vinculados con el control de la explotación de recursos provenientes de las Yungas por la quebrada de Huajra. Asimismo, habrían participado en redes de intercambio con sociedades de las tierras altas que incluiría a grupos instalados en la quebrada del Toro e incluso áreas lejanas como el norte de Chile.

A su vez, El Pobladito y P. Volcán presentan idiosincrasias propias que los diferencian de sitios más septentrionales de quebrada de Humahuaca (Cremonte y Fumagalli 1997). Las mismas darían cuenta del uso de variaciones en la cultura material como marcador de una identidad común dentro del sector centro-sur. En este sentido, las vasijas con engobe rojo fugitivo, escudillas evertidas de borde directo decoradas con bandas reticuladas en su borde interno y recintos rectangulares con ángulos redondeados son características ausentes en sitios más septentrionales como P.Tilcara (Ortiz y Delgado 2002; Otero 2013; Zaburlin 2009), Angosto Chico, Pucara de Perchel (Scaro 2009) y Pucara de Juella (Nielsen et al. 2004). La presencia de tales características daría cuenta del surgimiento de nuevas identidades y fronteras en la Quebrada durante el PIT. Esta idea ya fue propuesta por Ortiz y Delgado (2002), al comparar la colección Gatto de P.Volcán con la de P.Tilcara. Las autoras señalan que las escudillas de paredes rectas divergentes y borde directo decoradas con una banda reticulada en su borde interno predominan en P. Volcán, mientras que estas piezas están ausentes en P. Tilcara, donde las escudillas poseen perfiles evertidos simples de paredes subconvexas con asas. Asimismo, observaron un conjunto más limitado de diseños en las vasijas de P. Volcán. A partir de las diferencias observadas en ambos conjuntos, las autoras proponen que las características distintivas en cada colección reflejarían el surgimiento o consolidación de diversos nucleamientos políticos que habrían buscado expresiones estilísticas que manifiesten esa diferencia.

Diferencias entre los conjuntos alfareros del sector central y centro-sur de la quebrada fueron señalados también por Cremonte (2006) a nivel de pastas cerámicas, quien registró comportamientos diferenciales de manufactura entre alfarerías locales de P.Volcán y valles sudorientales con respecto a las de Tilcara.

Finalmente, la ausencia de evidencias de ocupación durante el período Incaico en El Pobladito, así como el mayor desarrollo de P.Volcán en este momento y el surgimiento de Esquina de Huajra y Las Ventanitas, reflejarían las modificaciones que la administración incaica introdujo en la articulación de los sitios del sector centro-sur, como fuera señalado por Cremonte et al. (2007). Así, El Pobladito habría sido desocupado, relocalizando a su población probablemente en P.Volcán o en los sitios localizados en los valles sudorientales (Fumagalli 2003), mientras que habrían surgido asentamientos más pequeños, como Esquina de Huajra y Las Ventanitas, este último probablemente vinculado con el control de la quebrada de Tumbaya Grande. 
Agradecimientos: Para esta investigación se utilizaron fondos de los proyectos PIPCONICET0060 y ANPCYT-PICT01538. Agradezco la colaboración de los alumnos de Antropología (FHyCS-UNJu) Nicolás Lamberti, Valeria López, Lautaro Geronazzo, Mariana Benavidez, Martín
Basso, José Tolaba y María Tejerina, así como a la Comunidad Aborigen de Tumbaya por el apoyo brindado a las investigaciones. Agradezco los comentarios realizados por Beatriz Cremonte y Emily Stovel, así como las sugerencias brindadas por los evaluadores de este trabajo.

\section{Referencias Citadas}

Agüero, C. y M. Uribe 2011. Las sociedades Formativas de San Pedro de Atacama: Asentamiento, cronología y proceso. Estudios Atacameños 42:53-78.

Arkush, E. 2008. War, chronology, and casualty in the Titicaca Basin. Latin American Antiquity 19:339-373.

Arkush, E. 2009. Más allá de los "señoríos aymaras": Territorio como red en la cuenca del Titicaca. Ponencia presentada en TANOA II, Jujuy.

Arkush, E. y T. Tung 2013. Patterns of war in the Andes from the Archaic to the Late Horizon: insights from settlement patterns and cranial trauma. Journal of Archaeological Research DOI 10.1007/s10814-013-9065-1.

Balfet, H., M. Fauvet-Berthelot y S. Monzon 1983. Pour la Normalisation de la Description des Poteries. Centre National de la Recherche Scientifique, Paris.

Bennett W., E. Bleiler y F. Sommer 1945. Northwest Argentine archaeology. Yale University Publications in Anthropology 38.

Bordach, M. 2006. Interacciones étnicas e indicadores de desigualdad social en el Cementerio de La Falda (SJTi143), Tilcara, Jujuy. Estudios Atacameños 31:115-128.

Bugliani, F. 2008. Consumo y Representación en el Sur de los Valles Calchaquíes (Noroeste Argentino). BAR, Oxford.

Conkey, M. y C. Hastorf (eds.) 1990. The Uses of Style in Archaeology. Cambridge University Press, Cambridge.

Cremonte, B. 2006. El estudio de la cerámica en la reconstrucción de las historias locales. El sur de la Quebrada de Humahuaca (Jujuy, Argentina) durante los Desarrollos Regionales e Incaico. Chungara Revista de Antropología Chilena 38:239-247.

Cremonte, B. y L. Botto 2009. Unas vasijas especiales halladas en contextos tardíos del noroeste de Argentina. Manufactura de los Pucos Bruñidos. Estudios Atacameños 37:63-77.

Cremonte, B. y M. Fumagalli 1997. El Pukara de Volcán en el sur de la Quebrada de Humahuaca ¿un eje articulador de las relaciones entre Yungas y tierras altas? Estudios Atacameños 14:175-188.

Cremonte, B. y G. Nieva 2003. Registro y clasificación cerámica del basurero TUM1B3 del Pukara de Volcán (Dto. Tumbaya, quebrada de Humahuaca). Cuadernos 20:273-391.

Cremonte, B. y N. Solís1998. La cerámica del Pucara de Volcán: variaciones locales y evidencias de interacción. En Los Desarrollos Locales y sus Territorios, compilado por B. Cremonte, pp. 155-196. Ediunju, Jujuy.
Cremonte, B., G. Ortiz y A. Delgado 1997. Las vasijas en los estantes. Análisis de una colección descontextualizada. Cuadernos 9:1-37.

Cremonte, B., S. Peralta y A. Scaro 2007. Esquina de Huajra (Tum10, Dto. Tumbaya, Jujuy). Avances en elconocimiento de una instalación Humahuaca-Inca y su integración en la historia prehispánica regional. Cuadernos del INAPL 21:27-38.

Cremonte, B., S. Peralta y A. Scaro 2011. Primera prospección arqueológica de un camino hacia y desde las Yungas (Dto. Tumbaya, Jujuy). Pacarina 6:81-90.

Debenedetti, S. 1930. Las ruinas del pucará. Tilcara, Quebrada de Humahuaca (Prov. de Jujuy). Archivos del Museo Etnográfico 11 (Primera parte).

Dougherty, B. 1974. Análisis de la variación medioambiental en la subregión arqueológica de San Francisco (Región Selvas Occidentales-subárea del NO argentino). Etnía 20:1-11.

Fumagalli, M. 1998. El Pucará de Volcán, historia ocupacional y patrón de instalación. En Los Desarrollos Locales y sus Territorios, compilado por B. Cremonte, pp. 131-153. Ediunju, Jujuy.

Fumagalli, M. 2003. Del formativo al incaico, los valles sudorientales de Jujuy en los procesos de interacción macroregionales. En La Mitad Verde del Mundo Andino, editado por B. Ventura y G. Ortiz, pp. 229-260. EdiUNJu, Jujuy.

Fumagalli, M. y B. Cremonte 2002. Ocupaciones agropastoriles tempranas al sur de la Quebrada deHumahuaca (Jujuy-Argentina). Chungara Revista de Antropología Chilena 34:35-52.

Gatto, S. 1946. Exploraciones arqueológicas en el Pucara de Volcán. Extracto de la Revista del Museo de La Plata(N.S.) 4:5-91.

González, R. y J. Pérez 1972. Argentina Indígena, Vísperas de la Conquista. Paidós, Buenos Aires.

Jernigan, E. 1986. A non-hierarchical approach to ceramic decoration analysis: A southwestern example. American Antiquity 51:3-20.

Knappett, C. 2005. Thinking through Material Culture. University of Pennsylvania Press, Philadelphia.

Martínez, G. 1989. Espacio y Pensamiento I. Andes Meridionales. Ed. Hisbol, La Paz.

Martínez, J. 1995. Autoridades en los Andes, los Atributos del Señor. PUCP, Lima.

Nielsen, A. 2001. Evolución social en quebrada de Humahuaca (AD700-1536). En Historia Argentina Prehispánica, editado por E. Berberian y A. Nielsen, pp. 171-261. Ed. Brujas, Córdoba. 
Nielsen, A. 2006. Pobres Jefes. Aspectos corporativos en las formaciones sociales pre-inkaicas de los Andes Circumpuneños. En Contra la Tiranía Tipológica en Arqueología, editado por C. Gnecco y C. Langebaek, pp. 121-150. Ediciones Uniandes, Bogotá.

Nielsen, A. 2007. Armas significantes: tramas culturales, guerra y cambio social en el sur andino prehispánico. Boletín del Museo Chileno de Arte Precolombino 12:9-41.

Nielsen, A., M. Hernández Llosas y C. Rivolta 2004. Nuevas investigaciones arqueológicas en Juella (Jujuy, Argentina). Estudios Sociales del NOA 7:93-116.

Ortiz, G. 2007. La Evolución del Uso del Espacio en las Tierras Bajas Jujeñas (Subárea del río San Francisco). Tesis Doctoral, Facultad de Filosofía y Humanidades, Universidad Nacional de Córdoba, Córdoba.

Ortiz, G. y A. Delgado 2002. Un lugar en el mundo. Estilo y territorio en Humahuaca. Gaceta Arqueológica Andina 26:193-206.

Otero, C. 2006. Análisis Cerámico del Recinto 2 de la Unidad 1, Sector Corrales del Asentamiento Urbanizado de Tilcara (SJujTil1-UH1). Tesis de Licenciatura, Facultad de Filosofía y Letras, Universidad de Buenos Aires, Buenos Aires.

Otero, C. 2013. Produccion, Uso y Circulación de Bienes en el Pucara de Tilcara (Quebrada de Humahuaca, Jujuy). Tesis Doctoral, Facultad de Filosofía y Letras, Universidad de Buenos Aires, Buenos Aires.

Platt, T. 2010. Desde la perspectiva de la isla. Guerra y transformación en un archipiélago vertical andino: Macha (Norte de Potosí, Bolivia). Chungara Revista de Antropología Chilena 42:297-324.

Rivolta, C. 2005. Cambio Social en la Quebrada de Humahuaca (1.100-1.400 d.C.). Instituto Interdisciplinario Tilcara, Tilcara.

Rivolta, C. 2007. Abandono y reutilización de sitio. La problemática de los contextos habitacionales en quebrada de Humahuaca. Estudios Atacameños 34:31-49.

Ruiz, M. y M. Albeck 1997. El fenómeno "pucara" visto desde la puna jujeña. Estudios Atacameños 12:75-87.

Santoro, C., A. Romero Guevara, V. Standen y A. Torres 2004. Continuidad y cambio en las comunidades locales, períodos Intermedio Tardío y Tardío, valles occidentales del área Centro
Sur Andina. Chungara Revista de Antropología Chilena 36 Volumen Especial Tomo I:235-247.

Scaro, A. 2009. El Pukara de Perchel (Til 4). Arqueología e Historia de un Lugar Estratégico en la Quebrada de Huamahuaca (Jujuy, Argentina). Tesis de Licenciatura, Facultad de Humanidades y Ciencias Sociales, Universidad Nacional de Jujuy, Jujuy.

Scaro A. y B. Cremonte 2012. La vajilla de servicio de Esquina de Huajra (Dpto. Tumbaya, Jujuy, Argentina). Alternativas teóricas para interpretar su significado. Revista del Museo de Antropología 5:31-44.

Schiappacasse, V., V. Castro y H. Niemeyer1989. Los desarrollos regionales en el Norte Grande (1000 a 1400 d.C.). En Prehistoria: Desde sus Orígenes hasta los Albores de la Conquista, editado por J. Hidalgo, V. Schiappacasse, H. Niemeyer, C. Aldunate e I. Solimano, pp. 181-220. Ed. Andrés Bello, Santiago.

Skibo, J. y G. Feinman 1999. Pottery and People. A Dynamic Interaction. University of Utah Press, Salt Lake City.

Solís, N. y A. Rivero 1994. Remoción de Masa en la Localidad de Tilcara. Prov. de Jujuy. Rep. Argentina. Actas III Simposio Latinoamericano sobre Riesgos Geológicos Urbanísticos, pp. 261-270. Cochabamba.

Taboada, C. 2003. Arquitectura y Sociedad en la Quebrada de Humahuaca Prehispánica. Tesis Doctoral, Facultad de Ciencias Naturales e Instituto M.Lillo, Universidad Nacional de Tucumán, Tucumán.

Tarragó, M. 1977. Relaciones prehispánicas entre San Pedro de Atacama (norte de Chile) y regiones aledañas: La Quebrada de Humahuaca. Estudios Atacameños 5:51-64.

Tarragó, M. 2000. Chakras y pukara. Desarrollos sociales tardíos. En Nueva Historia Argentina, dirigido por M. Tarragó, pp. 257-299. Ed. Sudamericana, Buenos Aires.

Torres-Rouff, C., M. Costa-Junqueira y A. Llagostera 2005. Violence in times of changes: the Late Intermediate Period in San Pedro de Atacama. Chungara Revista de Antropología Chilena 37:75-83.

Zaburlín, A. 2009. Historia de ocupación del Pucara de Tilcara: Jujuy, Argentina. Intersecciones 10:89-103.

\section{Notas}

1 Los elementos malacológicos fueron identificados por la Bióloga Ms.Sc. Nelly Vargas Rodríguez (Cátedra de Ecología, Facultad de Ciencias Agrarias, Universidad Nacional de Jujuy).

2 En su análisis morfológico, Cremonte et al. (1997) no consideran la dimensión temporal de las vasijas, pues trabajaron con material de la colección Gatto (1946). Sin embargo, a partir de los atributos considerados de acabado y tratamiento de superficie, separamos las formas que podrían corresponder al PIT, así de los 20 tipos determinados por las investigadoras, pudimos establecer nueve para este momento. 